remains shut up throughout the incubation period and until her brood is ready to fly, and during her incarceration goes through a complete moult. Towards the end of the year a pair of these birds selected a hole in a tall tree in the Botanical Gardens and had got as far as the walling in process when an interloper appeared on the scene and after a day of fierce fights stole the affections of the fickle female. Thereafter the jilted male for weeks came daily to the abandoned nesthole peering disconsolately into it and groaning and sobbing most mournfully.

\title{
THE INDIAN LION
}

(From a Report on the Lions of the Gir Forest by M. A. WynterBlyth.)

The Gir Forest in Kathiawar is the last home of the Asiatic lion. Up to the beginning of the last century the lion inhabited all suitable parts of north and central India, but the introduction of modern firearms and the spread of population led to its disappearance by 1884 from everywhere except Kathiawar. Even within Kathiawar the lions retired to the protection of the Gir Forest, except for irregular visits as far afield as the Barda Hills. This forest in southern Kathiawar in 1878 covered 1,200 square miles, but its area is now reduced by half. Much of it is thick forest of the mixed deciduous type, with teak predominating, but the undergrowth is fairly thin, allowing grazing of cattle and buffaloes throughout most of the area. In the eastern Gir there is grassland and scrubby bushes, including several kinds of acacia.

The Indian Lion differs little in appearance or size from the African, but is more shaggy and has a long tuft of hair at the end of the tail and on the elbow joints. The mane is scantier and varies in colour from tawny to grey.

The animals which form part of the lions' food include Chital, Four-horned Antelope, Wild Pig, Chinkara, Nilgai, and a few Sambar, but game is scarce and the lions seem to feed chiefly on cattle and buffaloes. Leopards are abundant and important in that they feed on many of the animals included in the lions' diet. Having little fear of man, it is not unusual for the lions to enter villages at night and kill cattle that are poorly secured. By day they lie up in the shade, especially of banyan trees or near waterholes. During the monsoon many lions leave 
the forest for its outskirts and the cultivated land nearby, probably following the cattle which move out at this time.

The history of the Gir lions since the beginning of this century is a good example of what can be achieved by careful protection. An official estimate in 1893 gave a total of 81 which dropped to 19 by 1900 . These figures cannot be taken as accurate but they show that the lions were in real danger of extinction. In 1899 1900 came the Great Kathiawar Famine when almost all the game in the Gir Forest died from lack of water and the lions were seriously affected. Lord Curzon who had been invited to shoot a lion, on hearing of the situation cancelled his visit and urged the Nawab to take immediate steps to save the animals from extinction. The Nawab agreed and from this dates the first attempt at their protection. During the next four years the lions, deprived of their normal food and maddened with hunger, became very bold, making constant attacks on domestic animals and human beings. Continual complaints were received from the surrounding villages of the damage done and toll taken of human life by lions ; nevertheless protection was not removed. Between 1904 and 1911 the lions seem to have changed their habits, probably owing to the return to normal conditions after the famine years and the increase of game. Never again were they a serious menace to human life and for the last thirty or forty years they have been tolerant of man. In 1913 reliable reports placed the number of lions at not more than 20 and it seemed that thcy were really on the verge of extinction. A ban was placed on shooting in Junagadh State by the Administrator, Mr. Rendall, and other states adjacent to the Gir were urged to do the same. Later on when the number of lions was assumed to have increased, a limited quota (about three a year) was shot and the present rules for protection were framed. These rules prohibited the shooting of lionesses and cubs, or any other shooting in the forest without special permission, and also banned shooting from any kind of vehicle. From 1920, when about 50 lions were reported, to 1936, was a time of steady increase. This was in spite of continued poaching from neighbouring states where there was a tendency to attract the animals over the border by tying up cattle. In 1936 a census was taken which produced a total of some 287 lions, but this was probably an overestimate, though it showed the success of protection.

The 1950 Lion Census.-In April, 1950, Mr. M. A. WinterBlyth carried out a census of the Gir lions, probably the biggest operation of its kind ever undertaken. He made three visits to the forest in 1948 and 1949 to explore the area and to make a 
test count. The census was held on 28 th and 29th April and was based on three factors ; that lions must drink at least once in the twenty-four hours, that they travel for preference along roads and paths, and that the pug measurements of two lions are seldom identical. At that time of year the roads and paths are covered with a fine dust, a perfect medium for recording pug marks. Unless unavoidable pug marks were not measured in coarse sand or shingle. The measurements taken were the length and breadth of the pug mark of the forefoot, and these were taken with specially prepared sticks, red for the first day, blue for the second, and red, white, and blue for the Baroda territory where counting also took place on the third day. The area covered was 700-800 square miles. Great care was taken in training the enumerators who worked in pairs counting from dawn to noon. The result of what seems to have been a most careful and painstaking census is a total of at least 219 to 227 lions, and a possibility of up to 250 lions.

In his report Mr. Winter-Blyth says that though it is probable that the lions decreased between 1936 and 1947 he is convinced that they are now on the increase, particularly as the census shows such a high proportion of young lions. This is highly satisfactory news, but there is certainly every need for continued vigilance. Permits to shoot male lions are now being granted at the rate of four a year, but Mr. Winter-Blyth advocates a census every two years and modifications in the numbers allowed if this should be necessary. He also suggests a rigid ban on all shooting of game in the Gir, except for the quota of lions and possibly leopards which have a similar diet. The forest contains a fair quantity of game, but hardly sufficient to feed some 250 lions. For really efficient management he recommends that the whole Gir Forest should be turned into a lion preserve with a responsible warden and adequate staff. Properly controlled afforestation and the prevention of jungle fires would greatly benefit the game. The scheme should, he says, be drawn up in conjunction with the Bombay Government to include that part of the Gir in Baroda.

In the carrying out of the 1950 census 233 enumerators and supervisors were employed, expenses amounting to approximately Rs. 2000/- (£150). 